\title{
Ensino colaborativo: uma possibilidade do Atendimento Educacional Especializado
}

\section{Resumo}

Em razão da perspectiva e efetivação da inclusão escolar, legislações sobre o Aendimento Educacional Especializado (AEE) e o desenvolvimento de políticas públicas para garantia da escolarização de alunos com necessidades educacionais especiais têm sido promulgadas no Brasil há mais de uma década. Estudos apontam que práticas pedagógicas de inclusão suscitam a organização de uma nova cultura escolar, o que envolve mais do que a oferta de um "atendimento educacional especializado". Nesta direção, a partir de pesquisas realizadas na área de educação especial e inclusão escolar, este texto tem por objetivos: analisar e refletir sobre as práticas pedagógicas que têm se configurado na proposta do Atendimento Educacional Especializado e apresentar, a partir de experiências desenvolvidas, dois casos que envolvem o ensino colaborativo como um sistema que se configura como uma possibilidade de AEE, para além da sala de recursos multifuncional.

Palavras-chave: Atendimento Educacional Especializado; Ensino Colaborativo; Inclusão Escolar.
Patricia Braun

Universidade do Estado do Rio de Janeiro - UERJ - RJ/Brasil braunpatriciao9@gmail.com

\section{Márcia Marin}

Colégio Pedro II - RJ/Brasil marinvianna2014@gmail.com

\section{Para citar este artigo:}

BRAUN, Patricia; MARIN, Márcia. Ensino colaborativo: uma possibilidade do Atendimento Educacional Especializado. Revista Linhas. Florianópolis, v. 17, n. 35, p. 193-215, set./dez. 2016. 


\title{
Collaborative teaching: a possibility of the Specialized Educational Service
}

\begin{abstract}
Due to the perspective and the effectiveness of school inclusion, legislation on Specialized Educational Services (SES) and development of public policies intended to ensure the schooling of students with special educational needs have been enacted in Brazil for more than a decade. Studies show that educational inclusion practices generate the organization of a new school culture, which involves more than the offer of a "specialized education". Accordingly, based on research conducted in the field of special education and school inclusion, this paper aims: to analyze teaching practices that have been set in the proposal of the Specialized Educational Services and to present two experience-based cases involving collaborative teaching as a system that is configured as a possible $\mathrm{SES}$, in addition to multifunctional classrooms.
\end{abstract}

Keywords: Specialized Educational Service; Collaborative Teaching; School Inclusion. . 


\section{Atendimento Educacional Especializado - contextualização}

O Atendimento Educacional Especializado (AEE) aparece nomeado na Constituição Federal (BRASIL, 1998), no artigo 208, como garantia à educação: "atendimento educacional especializado aos portadores de deficiência, preferencialmente na rede regular de ensino". No decorrer dos anos e, principalmente, nessa última década, normativas legais sobre o tema têm sido difundidas e, em consequência, ações têm sido implantadas no sistema educacional brasileiro, com vistas à escolarização de alunos que estão em turmas comuns e exigem respostas para suas necessidades de aprendizagem, pois apresentam demandas específicas em função de suas peculiaridades para aprender, principalmente pessoas com deficiência.

Atualmente, identifica-se o avanço de propostas legais com a finalidade de nortear a estrutura, organização, recursos, entre outros aspectos, em relação ao processo escolar desse alunado. Todavia, também é reconhecida a necessidade de análise e reflexão sobre as práticas pedagógicas desenvolvidas no Atendimento Educacional Especializado, a partir dessas normativas, no contexto da escola.

As propostas oficiais, em vigor, apresentam o Atendimento Educacional Especializado (AEE) como diretriz que orienta as ações de ensino numa "escola inclusiva", entre aspas porque a escola deve incluir a diversidade por inerência. Elas indicam a Sala de Recursos Multifuncional (SRM) como o espaço/tempo onde ocorrem tanto o atendimento complementar quanto o suplementar às estratégias pedagógicas comuns de ensino realizadas junto aos alunos com deficiência (intelectual, auditiva, visual, múltipla), altas habilidades e transtornos globais do desenvolvimento (BRASIL, 2009, 2010, 2011, 2014).

Assim, a implantação das Salas de Recursos Multifuncional apresenta-se como uma modalidade do Atendimento Educacional Especializado, porém, tem sido a única, pela condução e orientações dadas pelo Ministério da Educação (MEC). A Resolução $n^{\circ}$ 4/2009, do MEC/CNE (BRASIL, 2009) apresenta as diretrizes para este atendimento, conforme estabelecido no artigo $5^{\circ}$ : 
O AEE é realizado, prioritariamente, na sala de recursos multifuncionais da própria escola ou em outra escola de ensino regular, no turno inverso da escolarização, não sendo substitutivo às classes comuns, podendo ser realizado, também, em centro de Atendimento Educacional Especializado da rede pública ou de instituições comunitárias, confessionais ou filantrópicas sem fins lucrativos, conveniadas com a Secretaria de Educação ou órgão equivalente dos Estados, Distrito Federal ou dos Municípios.

A legislação diz que prioritariamente, mas não exclusivamente, o AEE acontece nas salas de recursos. Porém, na realidade elas tornaram-se sinônimo desse atendimento, como se não houvesse alternativas ao trabalho.

Muitas salas foram implantadas com distribuição de material específico. "De 2005 a 2009, foram oferecidas 15.551 salas de recursos multifuncionais, distribuídas em todos os estados e o Distrito Federal, atendidos 4.564 municípios brasileiros - $82 \%$ do total" ${ }^{1}$. As Salas de Recursos Multifuncionais são classificadas como tipo I e II, de acordo com os equipamentos, mobiliários e materiais didáticos pedagógicos que as compõem². E quem viabiliza essa proposta? Para melhor esclarecer, vale consultar atribuições do professor do AEE (BRASIL, 2009); é uma lista complexa e multifacetada.

Como formar esse docente tão especialista então? O Programa "Educação Inclusiva: direito à diversidade", elaborado e oferecido pelo MEC, ao longo da última década, teve como objetivo principal "apoiar a formação de gestores e educadores, a fim de transformar os sistemas educacionais em sistemas educacionais inclusivos"3. Com conteúdo variado, muita produção de material, oferta de vários cursos/formações presenciais e a distância, o programa formou professores para atuação nas salas de recursos multifuncional, sem, no entanto, atingir as proporções continentais do nosso país, razão pela qual nem todos os docentes tiveram acesso a ele. Mesmo assim, há uma pergunta a ser feita: é possível formar esse "supermultiprofessor"?

\footnotetext{
${ }^{1}<$ http://portal.mec.gov.br/implantacao-de-salas-de-recursos-multifuncionais >.

${ }^{2}$ Para maiores esclarecimentos, consultar:

$<$ http://portal.mec.gov.br/dmdocuments/salasmultifuncionais.pdf >.

${ }^{3}<$ http://portal.mec.gov.br/programa-saude-da-escola/194-secretarias-112877938/secad-educacao-

continuada-223369541/17434-programa-educacao-inclusiva-direito-a-diversidade-novo >.
} 
Estimamos ser pouco provável que os professores de SRM possam fazer e saber tudo que lá está listado, que, na verdade, se configura como o trabalho de uma equipe e não de um único profissional.

Diante disso, como tem acontecido o trabalho na SRM? Surgem aqui algumas ponderações sobre como as aprendizagens escolares ocorrem nesse contexto. Experiências vividas por nós, como docentes e pesquisadoras, no cotidiano das escolas, têm demonstrado que é recorrente uma desarticulação entre o trabalho realizado pelo professor de referência da turma comum e pelo professor de $\mathrm{AEE}$, pois não há tempo destinado aos planejamentos conjuntos e há profissionais que sequer se conhecem, principalmente se forem de escolas diferentes.

Existe um descompasso entre o que a escola espera do aluno e o que o AEE oferece, pois só a presença do estudante na turma comum não lhe garante aprendizagem sobre os mesmos componentes curriculares de seus pares. Há diversas indagações sobre como e o que deve ser trabalhado na sala de recursos e na sala de aula; qual seria o formato, tempo e tipo de ação didática ofertada pelo AEE, caracterizando-o como suplementar ou complementar, e não como substitutivo às ações na turma comum? Como garantir um trabalho articulado com a rotina diária, se reciprocamente os professores desconhecem a dinâmica que envolve o processo de ensino, justamente por não terem a oportunidade de compartilhar os mesmos espaços e tempo?

De acordo com alguns estudos (KASSAR, 2006; OLIVEIRA, 2007; PLETSCH, 2009; BRAUN, 2012; MARIN, 2015; SANTAROSA e CONFORTO 2015), os maiores impasses para o desenvolvimento do trabalho na SRM se apresentam com relação a alunos com deficiência intelectual e transtorno do espectro do autismo, lembrando que professores especialistas são necessários para ensinar braile, sorobã, LIBRAS, comunicação alternativa e ampliada, e que nem sempre têm formação para a necessidade do aluno. Mendes, Vilaronga e Zerbato (2014, p. 27) expõem que "cada professor de Educação Especial trabalha de uma forma, não havendo uma diretriz que oriente suas práticas pedagógicas diversas", ainda que haja diversas normativas sobre este atendimento.

Neste contexto, a premissa do processo de escolarização na concepção de inclusão escolar, como afirma Oliveira (2007, p.512), “deve ser capaz de atender a todos, indistintamente, sendo capaz de incorporar as diferenças no contexto da escola, o que 
exigirá a transformação de seu cotidiano e, certamente, o surgimento de novas formas de organização escolar [...]". Organizar um modelo de educação inclusiva requer um projeto que tenha por finalidade desenvolver práticas educativas equânimes para todos os alunos. Isto não é algo simples e exige mudanças significativas na estrutura escolar da qual dispomos, seja quanto ao tempo, espaços, concepções de ensino, de aprendizagem ou de currículo.

A escola é um ambiente de aprendizagens sociais e acadêmicas que se atravessam, se reforçam, se complementam e geram conhecimentos oriundos desse mesmo contexto composto pela diversidade de alunos. Por isso, não há a possibilidade de a escola se constituir como ambiente educacional somente por uma ou outra via. E, deste modo, corrobora esta perspectiva Ainscow (2001), ao afirmar que a intenção e a concepção previstas pela educação inclusiva requerem a garantia de um processo de escolarização baseado na presença, participação e construção de conhecimentos.

\section{Concepções teóricas desvelando uma realidade}

Outro aspecto, também inerente ao processo de escolarização para todos, é considerar que as aprendizagens que melhor se estruturam são as que se constituem pelo e no coletivo, nas trocas entre os pares - entre os mais e os menos experientes; que viabilizam modelos, pistas para a aprendizagem, com uma riqueza de possibilidades de compreender e de dialogar sobre o mesmo conceito por perspectivas variadas. Assim, além do aprendizado se caracterizar como uma das principais fontes para a elaboração de novos conceitos, ele é também uma poderosa força que direciona e determina o desenvolvimento dos sujeitos que estão em processo de escolarização.

A formação de conceitos "é mais do que uma soma de conexões associativas formadas pela memória; é um ato real e complexo do pensamento que não pode ser ensinado pelo treinamento" (VIGOTSKI, 2008, p. 104). Desse modo, o pensamento conceitual desenvolvido na escola a partir de sua base curricular, que aborda uma série de áreas de conhecimento, como explica Luria (2010), depende das operações teóricas que a criança aprende a realizar nesse lócus. Logo, a forma como o currículo é organizado tem reflexos sobre formação de conceitos de todos os alunos, mas com repercussões mais 
significativas sobre os que apresentam necessidades específicas de aprendizagem, dependendo das concepções pedagógicas e curriculares praticadas.

Com base nessas considerações, um modelo de atendimento que tem demonstrado certa eficácia é o sistema de ensino colaborativo, do qual trataremos a seguir.

\section{Ensino colaborativo como Atendimento Educacional Especializado}

Fontes (2007), Pletsch (2009), Milanesi (2012), Braun (2012), Marin (2015), Castro e Vaz (2015) apresentam estudos que assinalam a complexidade da escolarização de alunos com necessidades específicas de aprendizagem, principalmente com deficiência intelectual e autismo, e levantam questões sobre o Atendimento Educacional Especializado, proposto como Sala de Recursos Multifuncional, conforme normativas legais no país.

A partir de outros estudos, Mendes, Vilaronga e Zerbato (2014, p. 29) são claras ao retratarem o contexto atual deste sistema de suporte ao afirmarem que:

O que há de especial neste sistema de apoio, incluindo o aluno, seu professor e seu ensino, fica restrito ao ambiente especializado [...] enquanto a sala, a classe de aula comum permanece inalterada. A abordagem de atendimento é funcionalista porque se centra em compensar supostos déficits no aluno com deficiência.

Castro e Vaz (2015, p. 11) ratificam o olhar sobre as questões que comprometem a forma como o Atendimento Educacional Especializado tem sido proposto ao constatarem que há um expressivo “distanciamento entre os princípios que fundamentam as ações, encontrados nos documentos, e as práticas que deveriam consagrá-los”. E, neste sentido, afirmam que há "uma (im)possibilidade do AEE" no que se refere "ao trânsito entre responsabilização e aprendizagem sobre o processo de inclusão" para a escola e professores, pois as "possibilidades na prática estão aquém das apresentadas nos documentos aqui considerados". 
Em outras palavras, o que está proposto nas normativas não tem sido possível de realizar, considerando a efetiva aprendizagem. Mendes, Pletsch e Silva (2011, p. 262), já haviam indicado esta desarticulação ou a impossibilidade do sistema de apoio em prover o conhecimento sobre o processo de ensino e aprendizagem do aluno com deficiência intelectual, ao afirmarem que:

As trocas de experiência que poderiam possibilitar a constituição de novos habitus são solapadas por um cotidiano que impede o trabalho coletivo. Cada professor em sua sala de aula acaba sendo sujeito de práticas cristalizadas, acontecendo o mesmo com os professores dos serviços.

Com essas constatações, a possibilidade de uma proposta para o AEE passa a ser repensada, pois para ensinar o aluno com deficiência ou autismo, principalmente, é necessária uma dinâmica pedagógica, que ultrapasse o trabalho realizado no contraturno na SRM, com investimento em estratégias que contemplem ações docentes que permitam conhecer sobre o processo de aprendizagem do aluno, para favorecê-lo com um ensino adequado às suas necessidades.

Uma perspectiva considerada como promissora para práticas que estruturam melhor as ações do AEE é a proposta do ensino colaborativo, que tem sido referendado em pesquisas de cunho nacional (CAPELLINI e MENDES, 2007; MACHADO e ALMEIDA, 2010; TOLEDO e VITALIANO, 2012; VILARONGA e MENDES, 2014) e internacional (GLAZER e HANNAFIN, 2006; STANG e LYONS, 2008; RTHAUD et al., 2007). Como referência de discussão sobre essa estratégia, no Brasil, a Universidade Federal de São Carlos se destaca como responsável pelo início da disseminação de pesquisas com esse enfoque.

O sistema de ensino colaborativo

consiste em uma parceria entre os professores de Educação Regular e os professores de Educação Especial, na qual um educador comum e um educador especial dividem a responsabilidade de planejar, instruir e avaliar os procedimentos de ensino a um grupo heterogêneo de estudantes. (FERREIRA, MENDES, ALMEIDA, DEL PRETTE, 2007, p. 01) 
A proposta do ensino colaborativo, fundamentalmente, tem por finalidade a colaboração entre professores no desenvolvimento de atividades no cotidiano escolar, mais especificamente na sala de aula. Ou seja, todos os envolvidos no processo educacional compartilham as decisões tomadas e são responsáveis pela qualidade das ações efetivadas. Desse modo, não há uma sobreposição ou uma hierarquia entre a atuação de cada professor e sim relações que intentam "atingir objetivos comuns negociados pelo coletivo" a partir da "liderança compartilhada, confiança mútua e corresponsabilidade pela condução das ações" (DAMIANI, 2008, p. 214).

Compreendido como um modelo de coensino, o ensino colaborativo é apontado por Mendes, Vilaronga e Zerbato (2014, p. 26) como "um dos mais promissores suportes à inclusão", pois implica na transformação da estrutura escolar a partir da disponibilização de professores para oferecer suporte na sala de aula e, além disto, provoca "a formação de equipes colaborativas, a inserção dos recursos materiais necessários na sala de aula e a melhoria na qualidade de ensino para todos os alunos". Esta forma de propor ações para a realização do AEE é validada em algumas experiências na escola de educação básica, como a apresentada por Braun e Marin (2012, p. 09) uma vez que,

[...] revelam a importância de abordagens diferenciadas de ensino, tanto para o aluno que requer adequações, quanto para os demais alunos, os quais a partir dessas diferenciações acabam, também, sendo privilegiados com diversas possibilidades de aprender e demonstrar o aprendizado. Além disso, há uma compreensão mais contextualizada sobre a diversidade em sala de aula, sendo a mesma vislumbrada sob a perspectiva da possibilidade, com a busca de novos caminhos; tirando o foco dos limites ou das dificuldades como balizadores do fazer pedagógico do aluno.

Legalmente, cabe a análise a respeito do que está indicado nas normativas, embora não de forma explícita, sobre a ideia de colaboração entre os professores do AEE e do Núcleo Comum ${ }^{4}$. A Resolução n 02/01, por exemplo, que institui as Diretrizes Nacionais para a Educação Especial na Educação Básica, em seu art. $8^{\circ}$, diz que:

\footnotetext{
${ }^{4}$ A denominação Núcleo Comum é aqui utilizada em referência aos professores que atuam como regentes de turmas, desenvolvendo as atividades que envolvem as áreas de conhecimento de Língua Portuguesa,
} 
As escolas da rede regular de ensino devem prever e prover na organização de suas classes comuns: IV - serviços de apoio pedagógico especializado, realizado, nas classes comuns, mediante: a) atuação colaborativa de professor especializado em educação especial; b) atuação de professores-intérpretes das linguagens e códigos aplicáveis; c) atuação de professores e outros profissionais itinerantes intra e interinstitucionalmente; d) disponibilização de outros apoios necessários à aprendizagem, à locomoção e à comunicação (BRASIL, 2001, grifo nosso).

E, mais tarde, o Parecer $n^{\circ}$ 17/01, sobre as mesmas diretrizes, diz que "o corpo docente, e não cada professor, deverá partilhar a responsabilidade do ensino ministrado a crianças com necessidades especiais" (BRASIL, 2001, p. 7). Deste modo, ao citar "serviços de apoio pedagógico especializado, realizado, nas classes comuns", "atuação colaborativa", entre outros aspectos retirados das normativas acima citadas, os documentos fazem uma menção à atuação pedagógica com caráter colaborativo, ou seja, que o aluno com necessidades específicas de aprendizagem é responsabilidade de todos e não apenas do professor do AEE.

Assim, o ensino colaborativo apresenta-se como um modelo promissor para organizar estratégias de ensino para todos os alunos e também para colaborar com a formação docente. Isto é presumível a partir do momento em que professores compartilham saberes elaborados na docência com o aluno, como afirma Braun (2012). Estes conhecimentos, explicam Capellini e Mendes (2007, p. 118), “quando públicos, tornam-se saberes da ação pedagógica e formam um repertório de saberes disponíveis, capazes de auxiliar" o desenvolvimento do aluno e o professor na sua própria formação e constituição de práticas que se complementam e, por conseguinte, contribuem para a formação de um sistema educacional inclusivo.

Dois casos para comporem nossas reflexões... 


\section{Caso 01: O AEE para além da Sala de Recursos Multifuncional}

Este caso situa-se numa escola de educação básica, pública; é um colégio de aplicação que constitui-se como um instituto de uma universidade estadual. São em média 1100 alunos matriculados e, dentre eles, 18 alunos do ensino fundamental I e Ensino Médio apresentam algum tipo de necessidade educacional especial. As necessidades educacionais especiais com maior acesso à escola têm sido, até este momento, Transtorno do Espectro do Autismo (TEA), deficiência intelectual, deficiência física, deficiência auditiva e transtornos funcionais do desenvolvimento (como dislexia e TDAH).

O questionamento sobre como ensinar determinados estudantes surgiu no momento de ingresso de uma aluna, no $1^{\circ}$ ano do ensino fundamental I, com necessidades educacionais especiais significativas (auditiva, motora e intelectual), no início dos anos 2000. Como escola que tem por premissa o estudo e a aplicação de novas práticas para a formação inicial e continuada de professores, houve, de lá para cá, diversas iniciativas para estruturar o trabalho pedagógico de forma que viabilizasse o ensino dos alunos com necessidades educacionais especiais. Estes alunos têm acesso à escola por processo de sorteio (no $1^{\circ}$ ano) ou de seleção (no $6^{\circ}$ ano), considerando ainda um sistema de cotas para alunos com deficiência, aprovado no conselho superior da universidade em 2013.

A organização e estruturação das práticas sob o viés do ensino colaborativo tiveram seu início a partir de situações de formação inicial de alunos de licenciaturas, em projetos de iniciação à docência em 2007. Entretanto, com o ingresso sistemático, ano a ano, de alunos com necessidades educacionais especiais, uma equipe de professores foi estruturada para compor um trabalho pedagógico específico, denominando-se AEE Ensino Colaborativo, para além das ações dos projetos de iniciação à docência, coordenados por professoras com formação na área de educação especial e regentes de turmas do ensino fundamental I.

Dada a necessidade de uma estrutura de apoio pedagógico à escolarização de alunos com autismo e déficit cognitivo significativo, caracterizada pelos professores como as especificidades de maior demanda diante do processo de ensino e 
aprendizagem, a equipe do AEE - Ensino Colaborativo passou a atuar em uma proposta de intervenção pedagógica constituída por um conjunto de atividades, recursos de acessibilidade e ações de ensino. Esta se organiza institucional e continuamente com o objetivo de garantir a aprendizagem de todos os alunos, devendo ocorrer de forma colaborativa entre o professor do AEE e o professor da sala de aula, conforme indicado no Decreto $n^{\circ} 7611 / 11$ (BRASIL, 2011).

Nesta escola, são elegíveis ao AEE - Ensino Colaborativo, tanto os alunos segundo as normativas legais (deficiências, autismo, altas habilidades), quanto os que apresentam necessidades educacionais especiais relativas aos transtornos funcionais do desenvolvimento como o TDAH, dislexia, discalculia, disgrafia, entre outros transtornos que afetem significativamente a escolarização do aluno.

A configuração do acompanhamento dos professores do AEE - Ensino Colaborativo pode se dar sob as seguintes possibilidades: a) prioritariamente, em sala de aula, no acompanhamento das atividades da turma do aluno, quando há necessidade de mediação intensa para melhor interação com o processo de ensino, com os pares e com a dinâmica escolar; b) fora da sala de aula, ainda no turno do aluno, quando há necessidade de individualização no ensino, em alguns momentos, com a aplicação de recursos e estratégias mais diferenciadas em função da necessidade educacional específica e uso de planejamento individualizado; c) no contraturno, em pequenos grupos ou individualmente, quando não há necessidade retirar o aluno de sala, mas é preciso e possível ampliar, complementar ou suplementar as ações para a aprendizagem.

A proposta é o ensino a partir de outras linguagens e recursos, sem a repetição de procedimentos usados na sala de aula, levando em conta o planejamento geral da turma/ano escolar. E, tanto a forma quanto a intensidade do acompanhamento são dadas pela necessidade observada no desenvolvimento do aluno, durante o processo de escolarização, a qual é analisa pelos pares de professores do AEE - Ensino Colaborativo e do Núcleo Comum ou áreas disciplinares.

As ações, neste sentido, se apresentam melhor contextualizadas no $1^{\circ}$ segmento do Ensino Fundamental, por ter se caracterizado com estas demandas inicialmente. Com o avanço destes alunos na escolarização, estas ações começaram a ser requeridas a partir 
do $2^{\circ}$ segmento também. A proposta do AEE - Ensino Colaborativo é recente nesta escola, tendo sua primeira deliberação, que reconheceu e deliberou sobre o funcionamento do AEE, aprovada pelo conselho superior de ensino em 2014. O reconhecimento do modelo de apoio baseado no ensino colaborativo tem encaminhado propostas que galgam, em 2016, a constituição de um departamento de AEE para desenvolver ações pedagógicas transversais na escola.

Segundo Santos (2014, p. 36), ainda que este modelo seja novo para muitos professores, o qual requer a atuação colaborativa entre dois docentes, em sala de aula muitas vezes, "há indicativos de que esta estratégia tem enriquecido a prática pedagógica". Este fato é observado no fragmento que segue, retirado da pesquisa da autora supracitada, realizada na escola deste caso:

A presença de dois professores torna o processo de inclusão mais efetivo e consequentemente assertivo. Possibilita que o aluno seja atendido em suas necessidades, assim, a escola se adéqua às necessidades do educando e não o contrário. Nesse sentido, respeita-se a individualidade do educando, possibilitando que este ocupe seu lugar na sociedade. (fragmento retirado do questionário respondido pela Professora $\mathrm{R}$ )

Não obstante, no decorrer da constituição da estratégia de apoio caracterizada pelo AEE - Ensino Colaborativo, foram observados aspectos que merecem atenção. $O$ entendimento sobre a presença do professor do AEE como colaborador, numa situação de coensino, ocorreu de forma paulatina. Não foi algo dado, e ainda não o é, principalmente a partir do ensino fundamental II quando as ações começam a ser implantadas.

A configuração desta ação docente está atrelada a aspectos como: compreender e articular a flexibilização curricular; ter tempo para planejamento comum entre os professores; prever que impasses sobre como ensinar é algo real, pois não há receitas, principalmente diante de uma especificidade no desenvolvimento do aluno; definir qual o papel de cada professor no conjunto das ações pedagógicas; respeitar e rever formas de ensinar, gerando cumplicidade sobre o processo escolar; contar com suporte administrativo, pois a gestão da escola tem papel essencial na estruturação da proposta e 
dos recursos, e da visibilidade sobre a cultura escolar (MENDES et al., 2014).

Sobre este contexto, na mesma medida em que impasses surgem sobre a parceria entre os professores, o planejamento, a forma de oferecer o apoio, outros recursos necessários, novas possibilidades se configuram em relação ao fazer pedagógico. Na via do processo que segue e entende a necessidade de uma estrutura que apoie a escolarização dos alunos que chegam à escola, concursos específicos para o AEE são organizados, o diálogo e as relações entre professores se revelam mais cooperativos, conjugados na medida em que estes envolvidos se permitem fazê-lo e a gestão escolar favorece espaço, estrutura e diálogo para tal.

\section{Caso 02: O AEE na sala de aula}

O recorte aqui exposto é proveniente de uma pesquisa (MARIN, 2015) realizada numa escola pública da rede federal - equiparada, em 2012, aos Institutos Federais de Educação, Ciência e Tecnologia (IFEs). O estudo de caso envolveu uma turma dos anos escolares finais do ensino fundamental ( $8^{\circ}$ ano), na qual havia um aluno com deficiência intelectual e outro com Transtorno do Espectro do Autismo (TEA) - Síndrome de Asperger, inseridos numa turma de 27 estudantes, no ano de 2014. Do estudo, foram selecionados alguns aspectos significativos relacionados ao sistema de ensino colaborativo, que se apresentou como uma possibilidade de trabalho no contexto do Atendimento Educacional Especializado.

A instituição se compõe de vários campi, abrange da Educação Infantil ao Ensino Médio, tanto regular como técnico, ofertando ainda cursos de pós-graduação e educação para jovens e adultos. Nesse contexto, há um trabalho referente à inclusão escolar localizado no Núcleo de Atendimento às Pessoas com Necessidades Específicas (NAPNE) 5 Cada campus tem um, o do referido caso contava com uma professora de AEE - Ensino Colaborativo, que fez um curso de formação a distância, oferecido pelo MEC, para poder

\footnotetext{
${ }^{5} \mathrm{O}$ portal do MEC define a ação dos NAPNEs: "o Núcleo de atendimento às pessoas com necessidades educacionais específicas (NAPNE) prepara a instituição para receber as PNE, providenciando a adaptação de currículo conforme a necessidade de cada aluno". Conferir em:

http://portal.mec.gov.br/index.php?option=com_content\&id=12779\%3Aprograma-tec-nep\&ltemid=800
} 
atuar na função, o que a habilitou com conhecimentos básicos da área de educação especial.

Em 2011, comecei a atuar no segundo segmento, porque um aluno com Síndrome de Asperger estava indo para o $6^{\circ}$ ano.

Foi bem difícil... Foi um ano para interagir com os professores, que, de certa forma, demonstraram mais resistência, falta de conhecimento, menor disponibilidade... Ele acabou reprovado.

Nesse início de trabalho, outros alunos foram sendo indicados, foi um período de estruturação e construção da proposta, num movimento de conhecer essa dinâmica do segundo segmento. Foi tudo muito inicial...

[...] (Atualmente) faço um trabalho em sala, acompanhando alunos, durante a aula, num processo de mediação, como ensino colaborativo.

(Professora do AEE - entrevista)

A designação mediação em sala de aula está compreendida aqui como a inserção de um elemento de apoio ao trabalho pedagógico, cuja principal função é dar suporte ao estudante com necessidades educacionais especiais, na turma comum. Tem se chamado de mediador escolar, principalmente em escolas particulares, a uma pessoa que não precisa ser professora, nem possuir uma formação específica, pode ser um estagiário, que tem a incumbência de acompanhar a inclusão escolar do aluno especial (GLAT e PLETSCH, 2011; ARRUDA, 2013; CUNHA, 2013; ESTEF, 2013; MARIN e BRAUN, 2013), mas não é esse profissional que está sendo abordado aqui.

O que a professora de AEE - Ensino Colaborativo, do caso estudado, nomeia como 'mediação em sala de aula', designando o trabalho pedagógico realizado por ela, é caracteristicamente a estratégia do ensino colaborativo, que se constitui num modelo de serviço baseado na colaboração entre educação comum e especial, podendo ser denominada também de coensino ou bidocência (BEYER, 2005; FONTES, 2009; MENDES; VILARONGA; ZERBATO, 2014).

O propósito é garantir a articulação de saberes entre ensino especial e comum, combinando as habilidades dos dois professores. Assim, o professor regente da turma traz os saberes disciplinares, os conteúdos, o que prevê o currículo e o planejamento da escola, juntamente com os limites que enfrenta para ensinar o aluno com necessidade especial. $O$ professor do ensino especial, por sua vez, contribui com propostas de adequação curricular, atentando para as possibilidades do estudante, considerando as situações de ensino propostas e as opções 
metodológicas, planejando estratégias e elaborando recursos adequados para a promoção de sua aprendizagem. (MARIN e BRAUN, 2013, p. 53)

A professora explica como acontece o acompanhamento em sala, durante as aulas:

A dinâmica na sala é de mediar o conhecimento, principalmente, junto ao aluno com deficiência intelectual, mas a interlocução pode ser com qualquer aluno. [...] Na interação com eles, vou verificando o que sabem, onde têm dúvidas. Em sala, o maior apoio é a esse aluno; ao que tem Síndrome de Asperger, é para envolvê-lo nas tarefas. (Professora de AEEEnsino Colaborativo - entrevista)

Registros do diário de campo, de uma aula Geografia, ilustram um pouco dessa dinâmica:

A professora do AEE - Ensino Colaborativo está sentada entre o aluno com Síndrome de Asperger e o com Deficiência Intelectual, acompanhando com eles a aula; junto ao primeiro dá uns comandos orais e/ou gestuais para que ele fique atento, para que fique sentado, para registrar o que está no quadro. Para o segundo faz mais interação verbal, explicando novamente, com outras palavras, alguns conceitos que 0 professor apresenta.

Vai até a mesa de outro aluno, verifica o que está fazendo, dá um incentivo e volta a sentar-se entre os dois anteriores. Depois se levanta, vai até a mesa de uma amenina, Ihe fala algo e volta.

N.O. Seu olhar docente é atento ao que a turma de modo geral está fazendo, com atenção aos alunos individualmente, principalmente, aos que apresentam necessidades específicas. (Diário de campo - 12/04/2014)

Como pode ser visto, a prioridade da professora era o atendimento aos dois alunos, um com TEA e outro com DI, mas com um olhar atento a qualquer outro estudante. Os professores regentes, por sua vez, seguiam com suas aulas, com um pouco mais de atenção dirigida aos estudantes com necessidades específicas, sem qualquer alteração no programa curricular.

De acordo com o trabalho de campo, o ensino colaborativo mostrou-se como uma estratégia em construção na escola, sendo avaliada de modo positivo, conforme colocado por alguns professores. 
No início, eu achei que fosse uma pessoa que ia acabar se intrometendo, eu fiquei preocupada com isso, pensei: será que é uma que vai estar sempre interferindo?

Então, por um lado, eu achei que seria bom porque se eu não soubesse lidar com uma pessoa teria alguém para me ajudar, mas eu fiquei preocupada antes de conhecer... De ser uma pessoa que, talvez, estivesse sempre interferindo e questionando a forma como eu estou lidando, "ah! Você não pode ensinar assim" ou "você está falando rápido demais" ou "você está falando devagar demais", então eu fiquei um pouco preocupada com isso, mas depois que eu vi como ela trabalha, aí eu fiquei satisfeita, porque não dá para dar atenção para todos, principalmente o estudante com $\mathrm{DI}$, ele exige uma atenção muito especial.

(Professora de Matemática - entrevista)

Eu cheguei aqui esse ano, eu percebi que o trabalho era bem diferente, que há um desenvolvimento, um trabalho já construído; e, também, quando eu soube que existiriam essas professoras em sala comigo, eu achei muito interessante, é um trabalho compartilhado que, de fato, funciona. (Professora de Língua Portuguesa - entrevista)

Esse apoio que eles recebem é suficiente e eficiente, isso para eles poderem participar de igual para igual na sala de aula. (Professora de Ciências - entrevista)

É um estranhamento inicial, primeiro: "Por que aquele professor está ali assistindo a minha aula, será que de alguma maneira ele tem uma posição de fiscalização, policialesca em relação ao meu trabalho?" Então, essa questão da mediação é uma questão que também é muito nova aqui e, ainda que de maneira muito velada, encontra resistência que é absolutamente clara, pois o discurso não é esse, mas a prática é essa. (Professor de História - entrevista)

Um exemplo de colaboração fica evidenciado nesse episódio ocorrido na disciplina de História; a professora de AEE - Ensino Colaborativo começou a levantar material de apoio para que os alunos pudessem compreender melhor o conteúdo sobre a Revolução Francesa e consultou o professor sobre a validade; ele, por sua vez, trouxe para ela material pesquisado (filmes, documentários, fotos), numa construção mútua. O professor acabou passando um vídeo para a turma toda, que a outra professora havia indicado.

Na rotina, no entanto, alguns complicadores ficaram explicitados, entre eles destaca-se a relação entre número de alunos e de professores. Havia mais alunos em outras turmas que necessitavam do Ensino Colaborativo, que não puderam ser acompanhados porque só havia uma professora para realizar esse tipo de trabalho; o 
apoio pedagógico era realizado para esses outros estudantes, então, por aulas no contraturno e pela interação entre professores para orientações; uma alternativa pensada foi a de programar um sistema de itinerância para o Ensino Colaborativo, ou seja, estender o acompanhamento a alunos de outras turmas, entretanto, não houve articulação viável de horários, por falta de professor especializado.

A proporcionalidade numérica entre professores e alunos é um ponto a ser considerado na aplicação dessa alternativa de trabalho. Até o final de 2014, estavam oficialmente registrados seis alunos com deficiência intelectual no campus. Quantos professores especializados seriam necessários para realizar esse acompanhamento, se o critério fosse apoiar em sala só os alunos com DI?

Uma analogia é aqui apresentada para ilustrar a situação. Segundo o Censo de 2010 (CARTILHA DO CENSO 2010, 2012), 1,4\% da população brasileira tem deficiência intelectual. Por estes dados, o campus poderia ter cerca de 20 alunos com deficiência intelectual ( $1,4 \%$ do total de pouco mais de 1200 alunos). Se cada um estivesse numa turma diferente, haveria necessidade de um número de professores para atuarem no ensino colaborativo muito superior ao que comporta o quadro atual da instituição. Como equacionar isso?

É um aspecto que exige melhor atenção e maiores discussões; não há dúvida que a presença de um segundo professor em sala é um benefício para todos - tanto para docentes no âmbito da colaboração quanto para estudantes, com ou sem deficiência -, na medida em que o ensino ganha qualidade com a conjugação dos conhecimentos dos professores especializados e regentes das turmas, além de diminuir a razão numérica entre professor e aluno, o que permite aos docentes darem uma atenção aprofundada a um número menor de alunos. Porém, esta proposta é pouco viável em termos administrativos, pelo alto custo de operacionalização, na maioria das escolas, tanto na rede pública quanto privada.

Por essa e outras problematizações que não cabiam nesse espaço, o Ensino Colaborativo não pode ser considerado como uma panaceia da inclusão escolar, ele não é a solução para os impasses que se apresentam a esse paradigma, é uma entre outras possiblidades de trabalho e precisa ser melhor avaliado e ajustado. 
Apesar dos limites, é inegável a valorização que os professores regentes deram a esse trabalho, conforme o seguinte relato.

É uma experiência interessante também, você ter alguém...

Infelizmente, só tem ela pra escola inteira e toda turma tem sempre alguém que precisa de um apoio e ela tem essa facilidade no Ensino Fundamental, já no Ensino Médio, com outras disciplinas, com outras matérias, os alunos vão precisar, e não tem esse tipo de apoio para essas pessoas, eu perguntei para ela se não teriam outras pessoas para ajudar. Então acho que a escola, como um todo, tinha que se preocupar em ter mais profissionais especializados para poder trabalhar com esses alunos de forma mais intensa e ajudá-los melhor (Professora de Matemática entrevista).

\section{Considerações finais}

A organização de caminhos alternativos para aprendizagem de estudantes que exigem respostas educativas específicas indica que a "inclusão em educação pode ser vista (...) como um processo de transformação de valores em ação, resultando em práticas e serviços educacionais" (AINSCOW, 2009, p. 21). Como professoras de escola básica e pesquisadoras da área de educação especial, tentamos compreender o Atendimento Educacional Especializado por uma perspectiva mais ampla e, ao nos depararmos com a Sala de Recursos Multifuncional como sinônimo dessa ação sem atingir os objetivos propostos, fomos instigadas a pensar e a atuar em outras direções.

Vivenciamos na prática o ensino colaborativo como um Atendimento Educacional Especializado também, isso indica que outros serviços podem ser organizados para atender as necessidades de aprendizagem dos estudantes, de acordo com suas peculiaridades. A proposta do AEE, estruturada sob o viés do ensino colaborativo, apresenta-se como uma ação que possibilita resultados mais imediatos porque funciona em tempo real aos fatos ocorridos, possibilitando uma interação mais rápida entre os docentes para a intervenção pedagógica necessária.

As experiências aqui apresentadas, assim como outras, revelam que a parceria entre professores é uma ação que precisa ser disseminada, ainda que nem sempre seja sistemática ou tranquila. O sistema do ensino colaborativo como AEE sugere mudança 
sobre o fazer pedagógico, o que pode causar certo "desconforto". Deste modo, proposições precisam ser feitas para que tanto professores quanto estudantes tenham a possibilidade de exercerem suas funções e possibilidades no processo escolar.

A escola tem como finalidade promover aprendizagens e, para isso, todo procedimento que viabilizar tal meta deve ser estudado e aplicado para o bem coletivo, talvez não seja "mais fácil ou bom apenas para o professor. [Mas] esta meta tem que ser boa principalmente para o aluno", como afirmam Mendes et al. (2014, p. 126), o que endossamos. O ensino colaborativo é especialmente uma forma de apoio para a escolarização de todos os alunos.

\section{Referências}

ARRUDA, Samara Cliscia Alves de. Inclusão escolar e o papel da mediação. 2013. $62 \mathrm{f}$. Monografia (Licenciatura em Pedagogia) - Faculdade de Educação, Universidade do Estado do Rio de Janeiro, Rio de Janeiro, 2013.

ARTHAUD, Tamara; et al.. Developing collaboration skills in pre-service teachers: a partnership between general and special education. Teacher Education and Special Education, v. 30, n. 1, 2007, p. 1-12.AINSCOW, Mel. Desarrolo de escuelas inclusivas: ideas, propuestas y experiencias para mejorar las instituciones escolares. Madrid: Narcea, 2001.

AINSCOW, Mel. Tornar a educação inclusiva: como esta tarefa deve ser conceituada? In: FÁVERO, Osmar; FERREIRA, Windyz; IRELAND, Thimoty; BARREIRO, Débora. Tornar a educação inclusiva. Brasília: UNESCO, 2009, p.11-23.

BEYER, Hugo Otto. Pioneirismo da escola (modelo) Flämming na proposta de integração (inclusão) escolar na Alemanha: aspectos pedagógicos decorrentes. Revista Educação Especial. Universidade de Santa Maria/ Cascavel. n. 25, 2005, p. 9 - 24. Disponível em: <http://cascavel.ufsm.br/revistas/ojs-2.2.2/index.php/educacaoespecial/issue/view/245/ showToc> Acesso maio de 2014.

BRASIL. Constituição (1988). Constituição da República Federativa do Brasil. Brasília, DF: Senado, 1988.

BRASIL. Ministério da Educação. Parecer n.17/2001. Sobre as diretrizes nacionais para a educação especial na educação básica. Brasília, 2001. Disponível em: www.mec.gov.br Acesso maio 2016.

BRASIL. Ministério da Educação. Resolução n.04/09. Diretrizes Operacionais para o Atendimento Educacional Especializado na Educação Básica, modalidade Educação Especial, 2009. Disponível em: http://portal.mec.gov.br Acesso maio 2016. 
BRASIL. Ministério da Educação. Nota Técnica n. 11/10 SEESP/GAB. Orientações específicas sobre a institucionalização da oferta do atendimento educacional especializado em salas de recursos multifuncionais, em escolas regulares. Brasília, 2010. Disponível em: http://portal.mec.gov.br Acesso maio 2016.

BRASIL. Ministério da Educação. Decreto n. 7.611/11. Dispõe sobre a educação especial, o atendimento educacional especializado e dá outras providências. Brasília, 2011. Disponível em: http://www.planalto.gov.br Acesso maio 2016.

\section{BRASIL. Ministério da Educação. Nota Técnica n. 04 / 2014 / MEC / SECADI / DPEE.}

Orientação quanto a documentos comprobatórios de alunos com deficiência, transtornos globais do desenvolvimento e altas habilidades/superdotação no Censo Escolar. Brasília, 2014. Disponível em: http://portal.mec.gov.br Acesso maio 2016.

BRAUN, Patrícia. Uma intervenção colaborativa sobre os processos de ensino e aprendizagem do aluno com deficiência intelectual. 2012. 324 f. Tese (Doutorado) Universidade do Estado do Rio de Janeiro, Rio de Janeiro, 2012.

BRAUN, Patrícia; MARIN, Márcia. Práticas docentes em tempos de inclusão: uma experiência na escola básica. e-Mosaicos, Revista Multidisciplinar de Ensino, Pesquisa, Extensão e Cultura do Instituto de Aplicação Fernando Rodrigues da Silveira (CAp-UERJ), Ano 1, v.1, n. 2, p. 1-12. dez., 2012, Disponível em: <www.epublicacoes.uerj.br >. Acesso maio 2016.

CAPELLINI, Vera Lúcia; MENDES, Enicéia Gonçalves. O ensino colaborativo favorecendo o desenvolvimento para a inclusão escolar. Educere et Educare Revista de Educação, Cascavel/PR: UNIOESTE, v. 2, n. 4, p.113-128, 2007.

CASTRO, Juliana; VAZ, Alexandre Fernandez. Professores no Atendimento Educacional Especializado: Responsabilidades e Impossibilidades. Arquivos analíticos de políticas educativas, v. 23, n. 33, Arizona State University, 2015, p. 1-19. Disponível em: <http://epaa.asu.edu/ojs>. Acesso maio 2016.

CUNHA, Nathália Moreira da. O estagiário mediador na proposta de educação inclusiva: desafios e possibilidades. 2013. 83f. Monografia (Licenciatura em Pedagogia) - Faculdade de Educação, Universidade do Estado do Rio de Janeiro, Rio de Janeiro, 2013.

DAMIANI, Magda Floriana. Entendendo o ensino colaborativo em educação e revelando seus benefícios. Revista Educar. Curitiba: Editora UFPR, n. 31, 2008, p. 213-230.

FERREIRA, Bárbara Carvalho; MENDES, Enicéia Gonçalves; ALMEIDA, Maria Almeida; DEL PRETTE, Zilda Aparecida Pereira. Parceria colaborativa: descrição de uma experiência entre o ensino regular e especial. Revista do Centro de Educação/Cadernos, UFSM, n.29, p. 1-7, 2007.. Disponível em: <www.coralx.ufsm.br>. Acesso maio 2016.

FONTES, Rejane de Souza. Educação Inclusiva no município de Niterói (RJ): das propostas oficiais às experiências em sala de aula - o desafio da bidocência. 2007. Tese 
(Doutorado em Educação) - Universidade do Estado do Rio de Janeiro, Rio de Janeiro, 2007.

FONTES, Rejane de Souza. Ensino colaborativo: uma proposta de educação inclusiva. Araraquara (SP): Junqueira \& Marin, 2009.

GLAT, Rosana; PLETSCH, Márcia Denise. Inclusão escolar de alunos com necessidades especiais. Rio de Janeiro: EdUERJ, 2011.

GLAZER, Evan; HANNAFIN, Michel. The collaborative apprenticeship model: Situated professional development within school settings. Teaching and Teacher Education, v. 22, n. 2, p. 179-193, 2006,

KASSAR, Mônica de Carvalho. Quando eu entrei na escola.... Memórias de passagens escolares. Cadernos Cedes. Campinas, v. 26, n. 68, p. 60-73, 2006.

LURIA, Alexander Romanovich. Desenvolvimento cognitivo: seus fundamentos culturais

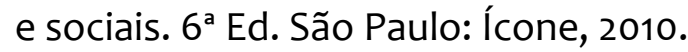

MACHADO, Andréa Carla; ALMEIDA, Maria Amélia. Parceria no contexto escolar: uma experiência de ensino colaborativo para educação inclusiva. Rev. Psicopedagogia, v. 27, n. 84, p. 344-351, 2010.

MARIN, Márcia. Inclusão escolar de alunos com necessidades educacionais especiais no segundo segmento do ensino fundamental em um espaço de excelência acadêmica. 2015. 194f. Tese (Doutorado) - Universidade do Estado do Rio de Janeiro. Rio de Janeiro, 2015.

MARIN, Márcia; BRAUN, Patrícia. Ensino colaborativo como prática de inclusão escolar. In: GLAT, Rosana; PLETSCH, Márcia Denise. Estratégias educacionais diferenciadas para alunos com necessidades especiais. Rio de Janeiro: EdUERJ, 2013. p. 49-64.

MENDES, Geovana Mendonça Lunardi; SILVA, Fabiany de Cássia Tavares; PLETSH, Márcia Denise Atendimento educacional especializado: por entre políticas, práticas e currículo um espaçotempo de inclusão?. Revista Contrapontos, Itajaí, SC., v. 11, n. 3, p. 255-265, out. 2011. ISSN 1984-7114. Disponível em: <http://siaiap32.univali.br>. Acesso maio 2016.

MENDES, Enicéia Gonçalves; VILARONGA, Carla Ariela Rios; ZERBATO, Ana Paula. Ensino Colaborativo como apoio à inclusão escolar: unindo esforços entre educação comum e especial. São Carlos: EdUFSCar, 2014.

MILANESI, Josiane Beltrame. Organização e funcionamento das salas de recursos multifuncionais em um município paulista. 2012. 185f. Dissertação (Mestrado em Educação Especial) - Universidade Federal de São Carlos, São Carlos, 2012.

OLIVEIRA, Anna Augusta Sampaio de. Um diálogo esquecido: a vez e a voz de adolescentes com deficiência. Editora Práxis, Bauru/SP, 2007. 
PLETSCH, Márcia Denise. Repensando a inclusão escolar de pessoas com deficiência mental: diretrizes políticas, currículo e práticas pedagógicas. 2009. Tese (Doutorado em Educação) - Universidade do Estado do Rio de Janeiro, Rio de Janeiro, 2009.

SANTAROSA, Lucila Maria Costi; CONFORTO, Débora. Tecnologias móveis na inclusão escolar e digital de estudantes com transtornos de espectro autista. Rev. bras. educ. espec., Marília, v. 21, n. 4, p. 349-66, 2015. Disponível em: <http://www.scielo.br>. Acesso em 30.03.2016.

SANTOS, Juliana Nathalia Pereira. Ensino colaborativo: uma proposta para a inclusão escolar? 2014. 45f. Monografia (Licenciatura em Pedagogia) - Universidade do Estado do Rio de Janeiro. Rio de Janeiro, 2014.

STANG, Kristin; LYONS, Bárbara. Effects of Modeling Collaborative Teaching for PreService Teachers. Teacher Education and Special Education, v. 31, n. 3, p. 182-194, 2008.

ESTEF, Suzanli. Ensino colaborativo sob o olhar de uma estagiária mediadora no cotidiano escolar. 2013. 65f. Monografia (Licenciatura em Pedagogia) - Faculdade de Educação, Universidade do Estado do Rio de Janeiro, Rio de Janeiro, 2013.

TOLEDO, Elizabete Humai; VITALIANO, Celia Regina. Formação de professores por meio de pesquisa colaborativa com vistas à inclusão de alunos com deficiência intelectual.

Revista Brasileira de Educação Especial, Marília, v. 18, n. 2, p. 177-358, 2012.

VILARONGA, Carla Ariela Rios; MENDES, Enicéia Gonçalves. Ensino colaborativo para o apoio à inclusão escolar: práticas colaborativas entre os professores. Revista Brasileira de Estudos Pedagógicos, Brasília, v. 95, n. 239, p. 139-151, abr., 2014. Disponível em: <http://www.scielo.br/scielo Acesso maio 2016>.

VYGOTSKY, Lev Semenovich. Pensamento e linguagem. 4. ed. São Paulo: Martins Fontes, 2008.

Recebido em: 15/03/2016 Aprovado em: 11/05/2016

Universidade do Estado de Santa Catarina - UDESC Programa de Pós-Graduação em Educação - PPGE

Revista Linhas

Volume 17 - Número 35 - Ano 2016 revistalinhas@gmail.com 